Reprod. Nutr. Dévelop., 1984, 24 (4), 343-350.

\title{
Semen characteristics of the muscovy drake (Cairina moschata) as affected by seasonal variation
}

\author{
G. GVARYAHU, B. ROBINZON, A. MELTZER, N. SNAPIR
}

Department of Animal Science, Faculty of Agriculture

The Hebrew University, P.O. Box 12, Rehovot 76100, Israel

Summary. Seasonal variations of semen characteristics of the Muscovy drake were examined between January and July, 1981. Interrelationships among semen characteristics and libido as affected by seasonal changes in temperature, humidity and daylight hours revealed the following : conditioning the Muscovy drake to give semen increased its libido and improved semen quality; in addition, peaks of sperm production occurred between the first week of March and the first week of April.

An increase in humidity at temperatures above $26-27^{\circ} \mathrm{C}$ induced thermal discomfort in the Muscovy drake, expressed by a significant decrease in sperm motility.

\section{Introduction.}

Few studies have been devoted to an investigation of the quantitative and qualitative characteristics of Muscovy drake semen, and only a few have examined the change in semen quality at particular seasons (Watanabe, 1961 ; Koll and Krause, 1979).

The purpose of the present investigation was to examine the influence of the following factors on Muscovy drake semen :

1) variation in duration of daylight within a 24-h period ;

2) changes in the temperature and humidity of the environment ;

3) variation in drake libido ;

4) the interaction between these three parameters.

\section{Material and methods.}

Animals. - Sexually mature Muscovy drakes, aged 6-7 months, were used in their first period of fertility. They were kept under natural light in individual pens $(2.5 \times 1.5 \mathrm{~m})$ and fed goose breeder mash and water ad lib.

Method of semen collection. - This method was based on the artificial vagina method (Tan, 1980 ; Gvaryahu et al., 1984).

Experimental procedure. - Semen was obtained from 5 Muscovy drakes once a week from the end of January until the end of July 1981. The semen was characterized within 5 min of collection time. 
Semen characteristics. - Semen volume was determined by collecting the semen in a test tube especially designed for the purpose (Gvaryahu et al., 1984). Sperm concentration was measured using the microspermatocrit method (Taneja and Gowe, 1961) calibrated for an absolute number of spermatozoa by a hemocytometer. Sperm motility was graded according to Pistenma et al. (1971) on a scale of 0 to 5 .

Drake libido. - The libido of the Muscovy drake was examined using an arbitrary measurement. A drake that demonstrated typical mating behavior towards the female without preliminary courtship behavior and reached erection quickly was ranked as 5 . Those drakes not responding at all were ranked as 0 . The remainder of the drakes were ranked between 0 and 5 according to the length of courtship.

Measurement of temperature and humidity. - Measurements were taken by the meteorological station located close-by the drake pens.

Statistical analysis. - Analysis was carried out using ANOVA and Duncan's multiple range test (Brounlee, 1965).

\section{Results.}

The weekly fluctuation of semen volume, sperm concentration and total number of spermatozoa per ejaculate are presented on figure 1. Figure 2 shows

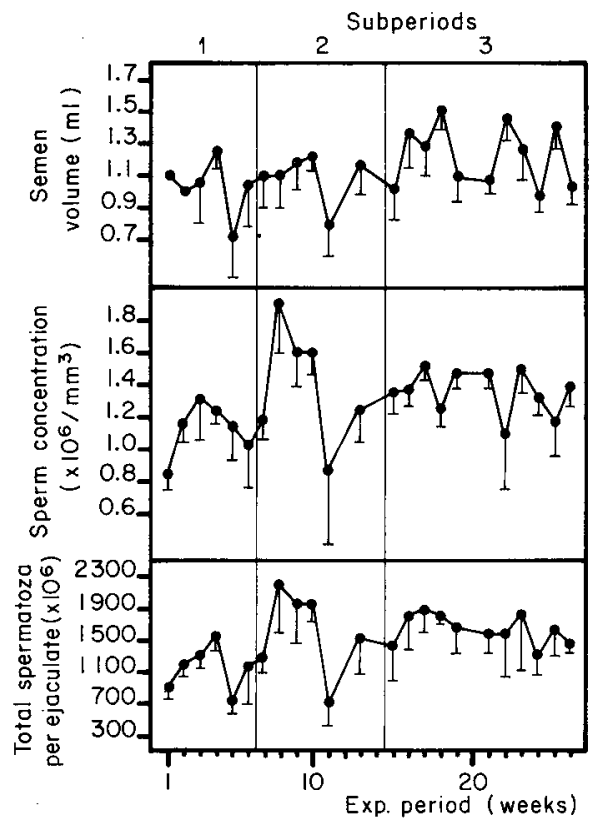

FIG. 1. - Weekly fluctuations of semen volume, sperm concentration and total number of spermatozoa per ejaculate (means \pm SE). (January to July 1981). 


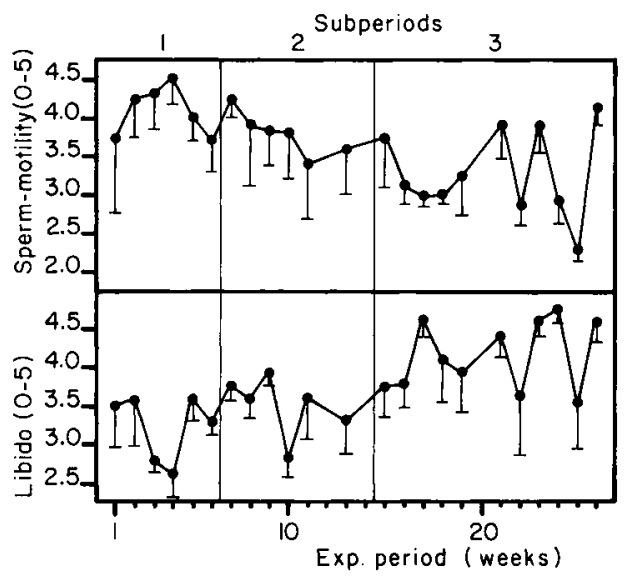

FIG. 2. - Week/y fluctuations of sperm motility and libido (means \pm SE) (January to July 1981). Libido $-\hat{\mathrm{Y}}=3.03+0.058 \times(\mathrm{P}=<0.01) ; \mathrm{r}=0.678(\mathrm{P}=<0.01)$.

Sperm-motility $-\hat{\mathrm{Y}}=4.24-0.0514 \times(\mathbf{P}=<0.01) ; r=-0.620(\mathbf{P}=<0.01)$.

the weekly fluctuations in sperm motility and libido. Weekly temperature rangeproduct (min. temp. $\times$ max. temp.), humidity range product (min. humidity $\times$ max. humidity) and humidity-temperature range product (temp. range product $x$ humidity range product) are shown on figure 3 . The alteration of daylight hours

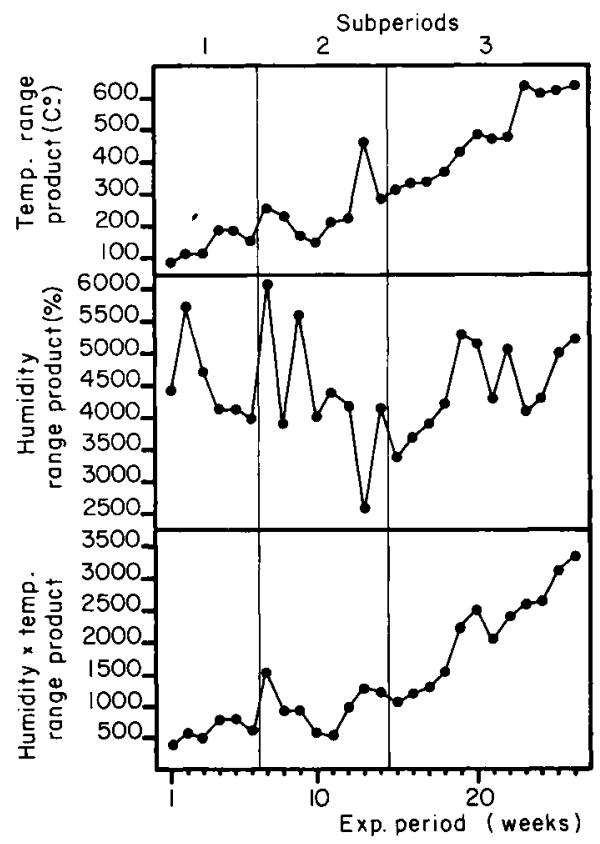

FIG. 3. - Weekly averages of climatic conditions (January to July 1981). 


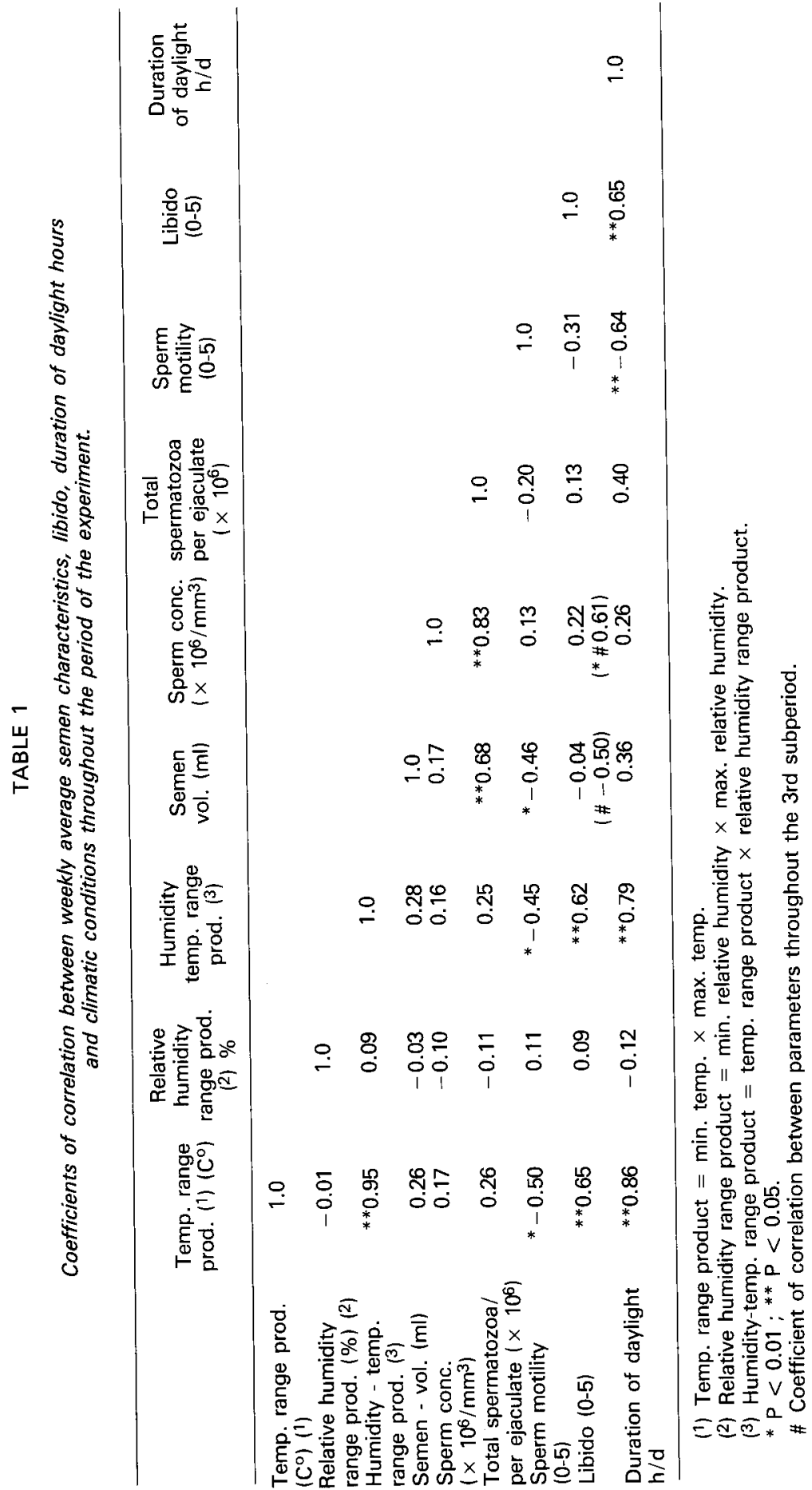




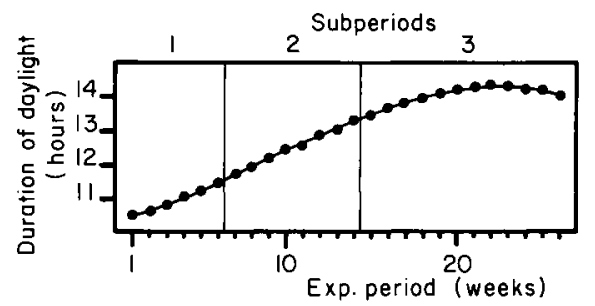

FIG. 4. - Week/y averages of daylight duration (hours) from January to July.

during the experimental period is presented on figure 4 . Table 1 presents the correlation coefficients between the various semen characteristics, libido, duration of daylight hours, and climatic conditions throughout the experimental period. A significant and positive correlation was found between drake libido and the temperature range product, temperature humidity range product and duration of daylight hours. A negative significant correlation was found between the rate of sperm motility and the following : duration of daylight hours, temperature-range product, temperature-humidity range product and semen volume. A positive signifiant correlation was found between the duration of daylight hours and temperature range product as well as temp. $\times$ humidity range product.

The experimental period (January 1 to July 25, 1981) was subdivided into three different periods according to changes in the temperature-range product (Perek and Snapir, 1963), as follows: subperiod 1, the first 6 weeks; subperiod 2, the following 8 weeks ; subperiod 3, the last 12 weeks. In these periods, the temperature product ranged between 90-190, 200-300 and 300-600, respectively.

The results of statistical analysis between the average semen characteristics and libido during the different subperiods are shown on table 2 . There was a

TABLE 2

Subperiod averages $( \pm \mathrm{SE})$ of semen characteristics and libido of five drakes, including significance tests between these averages

\begin{tabular}{|c|c|c|c|}
\hline & $\begin{array}{l}\text { Subperiod } \\
1\end{array}$ & $\begin{array}{l}\text { Subperiod } \\
2\end{array}$ & $\begin{array}{l}\text { Subperiod } \\
3\end{array}$ \\
\hline Semen-volume $(\mathrm{ml})$ & $1.01 \pm \underset{(a)}{0.10\left(^{*}\right)}$ & $1.08 \underset{(a)}{ \pm} 0.08$ & $1.19 \underset{(\mathrm{a})}{ \pm} 0.05$ \\
\hline Sperm concentration $\left(\times 10^{6} / \mathrm{mm}\right)$ & $1.12 \pm \underset{\text { (b) }}{0.09}$ & $1.43 \pm 0.12$ & $1.37 \underset{(\mathrm{a})}{ \pm} 0.06$ \\
\hline $\begin{array}{l}\text { Total spermatozoa per ejaculate } \\
\left(\times 10^{6}\right)\end{array}$ & $1103 \pm \underset{(b)}{ \pm 133}$ & $1563 \underset{\text { (a) }}{ \pm} 186$ & $1600 \pm 108$ \\
\hline $\begin{array}{l}\text { Sperm motility }(0-5) \\
\text { (arbitrary measurement) }\end{array}$ & $4.07 \underset{\text { (a) }}{ \pm} 0.17$ & $3.78 \underset{(a)}{ \pm} 0.24$ & $3.28 \underset{\text { (b) }}{ \pm} 0.15$ \\
\hline $\begin{array}{l}\text { Libido }(0-5) \\
\text { (arbitrary measurement) }\end{array}$ & $3.22 \pm 0.16$ & $3.47 \underset{\text { (b) }}{ \pm} 0.14$ & $4.17 \underset{(\mathrm{a})}{ \pm} 0.12$ \\
\hline
\end{tabular}

$\left.{ }^{*}\right)$ Figures with different subscripts are statistically different from each other $(P<0.05)$. 
significant increase in sperm concentration and the number of total spermatozoa per ejaculate during transition from the first to the second subperiod, a significant decrease in sperm motility and a significant increase in libido during the third subperiod. Regression lines and correlation tests also showed the decrease in sperm motility and the increase in libido to be significant throughout the experimental period (fig. 2).

It should be emphasized that, in addition to changes in the total number of spermatozoa per ejaculate between the subperiods, there was a peak in this parameter between the first week of March and the first week of April (fig. 1).

\section{Discussion.}

To simplify the discussion, an arbitrary division has been made between the various elements that were believed to have influenced the characteristics of Muscovy drake semen.

Libido. - The results of the present study show that Muscovy drake sexual response became a trained reflex and increased as the period of semen collection progressed.

When a method of semen collection similar to the one used here was applied to deer, the regular repetition of semen collection transformed sexual response into a conditioned reflex (Sokolova, 1945).

The significant correlation between libido and duration of daylight hours may be partially due to the increase in daylength during the experimental period. It is quite possible that, as sexual activity increased due to lengthening of daylight hours, it became easier to train the drake to give semen. Since the temperature range product increased during the experimental period, the positive and significant correlation found between the libido and this parameter might be secondary to the gradual progression of daylight hours and of the length of the drake training period.

During the third experimental subperiod, when the drakes ejaculated after showing only minimal courtship behavior, we found a negative correlation between volume and libido as well as a significant, positive correlation between libido and sperm concentration. Fujihara and Nishiyama (1976) reported that lymphatic fluids secreted by the ejaculatory groove region were added to the semen. It may be that at minimal libido, the drake is in a state of continuous selfstimulation in which the ejaculatory groove region collects lymphatic fluid. Thus, as long as courtship and self-stimulation continue, the volume of fluid added to the semen increases.

Duration of daylight. - In the present study, a significant increase in Muscovy drake sperm production occurred between the first week of March and the first week of April ; this production was at a peak during the third week of March. Peaks of sexual activity and sperm production were found in FebruaryMarch, September and June (Watanabe, 1961), September and May-June (Marchand and Gomot, 1973), and in May (Koll and Krause, 1979). 
The Muscovy duck originated in Mexico and Brazil, and its geographical distribution is concentrated primarily between the 0 and 20th latitudes (Delacoar, 1959). The reproductive season in these regions ranges from March to May (Phillips, 1922). It may be suggested that no significant changes appear to have occurred in the reproductive season of Muscovy duck during the period of its domestication.

Temperature-Humidity. - Decrease of fertility due to low semen quality in the summer heat was reported in rams, chickens and bulls (Cupps et al., 1960 ; Kamar and Badreldin, 1959 ; Schindler et al., 1957; Erb et al., 1942). In the present study of the Muscovy drake, a significant negative correlation between the rate of sperm motility and temperature range product as well as temperature humidity range product was found during the experimental period (table 1). A significant decrease in sperm motility was found only from the 15th week of the experiment and thereafter, when the environmental temperature reached $26-27{ }^{\circ} \mathrm{C}$ (table 2). Under the present experimental conditions, there was a positive correlation between temperature and humidity during the summer. Therefore, in addition to increased environmental temperature per se, the drakes were also inconvenienced by thermal discomfort induced by a parallel increase in humidity at temperatures above $26-27{ }^{\circ} \mathrm{C}$. The negative correlation between duration of daylight hours and sperm motility may be linked to the fact that in Israel there is a positive correlation between temperature increase and duration of daylight hours.

\section{Conclusions.}

I. Conditioning the Muscovy drake to ejaculate was found to improve semen quality.

II. Increased humidity at temperatures above $26-27{ }^{\circ} \mathrm{C}$ induced thermal discomfort in the Muscovy drake, expressed by a significant decrease in sperm motility.

III. Peaks of Muscovy drake sperm production occurred between the first week of March and the first week of April.

Reçu en août 1983.

Accepté en février 1984.

Acknowledgements. - The authors gratefully acknowledge the support of this study by the Taube Family Research Grant in Animal Husbandry, Hebrew University of Jerusalem, Faculty of Agriculture.

Résumé. Caractéristiques du sperme de canard de Barbarie (Cairina moschata). Influence des variations saisonnières.

Les changements saisonniers des caractéristiques de la semence du canard de Barbarie ont été examinés de janvier à juillet 1981. Les relations entre les caractéristiques de la semence et l'instinct sexuel (la libido) ont été influencées par les variations saisonnières de la température, de I'humidité et de la longueur de la journée. Les résultats suivants ont 
également été obtenus : le conditionnement de la production de semence est lié à l'intensification de la libido et à l'amélioration de la qualité du sperme. Des pics de production de semence ont été notés entre la première semaine du mois de mars et la première semaine du mois d'avril.

Une élévation de l'humidité à des températures au-dessus de $26-27^{\circ} \mathrm{C}$ cause un inconfort thermique au canard de Barbarie, qui s'exprime par une baisse significative de la motilité du sperme.

\section{References}

BROUNLEE K. A., 1965. Statistical theory and methodology in science and engineering. 2nd ed., Wiley, New York.

CUPPS P. T., McGOWAN B., RAHLMANN D. F., REDDON A. R., WEIR W. C., 1960. Seasonal changes in the semen of rams. Anim. Sci., 19, 208-213.

DELACOAR J., 1959. The waterfowl of the world, Vol. I, II, III. Country Life Ltd., London.

ERB R. E., ANDREWS F. N., HILTON J. H., 1942. Seasonal variation in semen quality of the dairy bull. J. Dairy Sci., 25, 815-826.

FUJIHARA N., NISHIYAMA H., 1976. Studies on the accessory reproductive organs in the drake. 3. Ejecting mechanism of the fluid from the ejaculatory groove region. Poultry Sci., 55, 10261030.

GVARYAHU G., ROBINZON B., MELTZER A., PEREK M., SNAPIR N., 1984. An improved method for obtaining semen from Muscovy drakes and some of its quantitative and qualitative characteristics. Poultry Sci., 63, 548-553.

KAMAR G. A. R., BADRELDIN A. L., 1959. Seasonal variations in semen characteristics of adult fayomi cocks. Poultry Sci., 38, 301-315.

KOLL H., KRAUSE D., 1979. Investigations on semen from Muscovy duck, Cairina moschata, and artificial insemination for the production of hybrid broilers. Zuchthygiene, 14, 80.

MARCHAND C. R., GOMOT L., 1973. Le cycle testiculaire du Canard de Barbarie (Cairina moschata L.1. Bull. Assoc. Anat., 58, 367-374.

PEREK M., SNAPIR N., 1963. Seasonal variations in semen production of different breeds of cocks and the effect of vitamin $C$ feed supplementation upon the semen of White Rocks. Brit. Poultry Sci., 4, 19-26.

PHILLIPS J. C., 1922. A natural history of the ducks, Vol. I. Houghton-Mifflin Co., Boston.

PISTENMA P. A., SNAPIR N., MEL H. C., 1971. Biophysical characterization of fowl spermatozoa. 1. Preservation of motility and fertilizing capacity under conditions of low temperature and low sperm concentrations. J. Reprod. Fert., 24, 153-160.

SCHINDLER H., VOLKANI R., WEINSTEIN S. H., 1957. A note on seasonal fluctuations in the motility of cock semen. Poultry Sci, 36, 194-196.

SOKOLOVA L. M., 1945. A study of conditioned sexual reflexes in rams. Trud. Lab. isskust. Osemen. Zivotn. (Mosk.), 1, 23-25. Cited in : Anim. Breed. Abstr., 13, 36.

TAN N. S., 1980. The training of drakes for semen collection. Ann. Zootech., 29, 93-102.

TANEJA C. G., GOWE R. S., 1961. Spermatozoa concentration in the semen of two breeds of fowl estimated by three different methods. Poultry Sci., 40, 608-615.

WATANABE M., 1961. Experimental studies on the artificial insemination of domestic ducks, with special reference to the production of mule ducks. J. Fac. Fish. anim. Husb. Hiroshima Univ., 3, 439-485. 